\title{
Multi objective prediction and optimization of control parameters of Friction stir welding on Casted AlSi10Mg plates with Taguchi - Gray Relational Analysis
}

\author{
Balakrishna G ${ }^{1,}{ }^{*}$, B Raghukumar ${ }^{1}$ and B Balakrishna ${ }^{2}$ \\ ${ }^{1}$ Department of Mechanical Engineering, PVPSIT, Kanuru, Vijayawada, A.P, India. \\ ${ }^{2}$ Department of Mechanical Engineering, JNTUK, Kakinada, A.P, India.
}

Global Journal of Engineering and Technology Advances, 2021, 08(01), 001-009

Publication history: Received on 25 May 2021; revised on 30 June 2021; accepted on 02 July 2021

Article DOI: https://doi.org/10.30574/gjeta.2021.8.1.0095

\begin{abstract}
In this study, a $3 \mathrm{~mm}$ thickness of AlSi10Mg Casted alloy plates was used in the friction stir welding process. The experimentations were conducted Using design of experiment to shorten the number of experiments and to get optimal friction stir welding parameters by utilizing Gray relational analysis based on the ultimate tensile and hardness test results. Orthogonal array of L9 $\left(3^{3}\right)$ was used based on three main parameters and three stages for each parameter, where tool velocity of three stages are 800, 900 and $1000 \mathrm{Rpm}$, tool feed of 30,40,50 mm/min, plus axial load of 300,400 and $500 \mathrm{Kg}$. Using Minitab 17 software. Gray Relational analysis is used to explore the optimal set of process variables and their effects on the ultimate tensile strength and hardness of weld plates. The plates are effectively welded, tensile test and hardness is measured at room temperature. The end result shows that the tool velocity $1000 \mathrm{rpm}$, feed $50 \mathrm{~mm}$ / min, then axial load of $400 \mathrm{~kg}$ are dominant process parameters to join AlSi10Mg Casted alloy plates.
\end{abstract}

Keywords: Friction stir welding; AlSi10Mg casted alloy; Taguchi technique; Gray Relational Analysis; Ultimate Tensile strength, Hardness

\section{Introduction}

The need for high strength to weight ratio is continuously growing especially in automobiles and aviation sector in improving fuel efficiency and reducing harmful emissions [1]. AlSi10Mg alloy belongs to hypoeutectic aluminum alloys group. It is frequently used in automotive, aircraft and armed applications because of superior mechanical properties combined with low strength to weight ratio, corrosion resistance and quite decent castability [2]. The presence of Eutectic $\mathrm{Al}+\mathrm{Si}$ phase in this alloy has greatly effects ductility and strength, and also effects machinability. One of the significant characteristics of AlSi10Mg alloy are low shrinkage and melting point, hence this alloy is highly suitable candidate for casting. FSW (friction stir welding) is solid state joining technique. Especially well-suited to aluminum alloys, even though much care is taken in welding, these are difficult to fusion weld without experiencing hot cracking, porosity, or distortion. The rotating tool's Frictional heat and plastic flow cause major microstructure changes, resulting in variations in the weld's quality on mechanical properties [3]. A nugget or a stir region, a thermo-mechanically affected zone (TMAZ), and a heat affected zone make up the FSW zone (HAZ). The stir zone's grain structure is exceptionally equiaxed and extremely fine, resulting in improved ductility and mechanical endurance [4]. In FSW, the plates are heated to a temperature of one third of its melting point of metal hence the mechanical properties of the welded region, such as ductility and strength, are much higher than in conventional techniques [5-7]. Here, welding process optimization is the primary concern in order to achieve an improved weld joint, as incorrect chosen parameter leads to tool failure and lower weld efficiency. Researchers use a number of optimization methods, such as Taguchi, Grey relation analysis, and ANN, to arrive at the best solution for industrial problems $[8,9]$.

\footnotetext{
${ }^{*}$ Corresponding author: Balakrishna G

Department of Mechanical Engineering, PVPSIT, Kanuru, Vijayawada, A.P, India.
} 


\section{Experimental Work}

In this work, AlSi10Mg casted alloy manufactured through casting process is used for experimentation work. $100 \mathrm{~mm}$ long $50 \mathrm{~mm}$ width and $3 \mathrm{~mm}$ thick Plates are obtained by wire EDM and Spectrometric analysis of chemical composition (Table 1) was also included.

Table 1 AlSi10Mg alloy chemical composition after casting

\begin{tabular}{|c|c|c|c|c|c|c|c|c|c|c|}
\hline Si & $\mathbf{M g}$ & $\mathbf{C u}$ & $\mathbf{M n}$ & $\mathbf{F e}$ & $\mathbf{N i}$ & $\mathbf{Z n}$ & $\mathbf{P b}$ & $\mathbf{S n}$ & $\mathbf{T i}$ & $\mathbf{A l}$ \\
\hline $9.0-11.0$ & $0.2-0.43$ & $\leq 0.05$ & $\leq 0.47$ & $\leq 0.58$ & $\leq 0.05$ & $\leq 0.1$ & $\leq 0.05$ & $\leq 0.05$ & $\leq 0.15$ & Balance \\
\hline
\end{tabular}

In this work, FSW is used to join AlSi10Mg alloy plates using R.V. Machine tools make with 3 ton capacity equipped with CNC control. The tool used to join AlSi10Mg plates fabricated by using H13 grade tool steel with $12 \mathrm{~mm}$ diameter shoulder and straight cylindrical pin with $4 \mathrm{~mm}$ diameter and $2.8 \mathrm{~mm}$ length, shown in fig.1. Prior to welding, edges were thoroughly cleaned by mechanical method and applied ethanol solution, to make sure edges are free from any contamination. Then the plates are rigidly clamped on to the FSW machine table using clamps and T-bolts. Three FSW parameters were selected with three levels shown in table.2. Friction stir welding carried out using 9 different parameter combinations that were derived using Taguchi's DOE concept. Gray relational method is used to study the response of output parameters over input parameters [5].

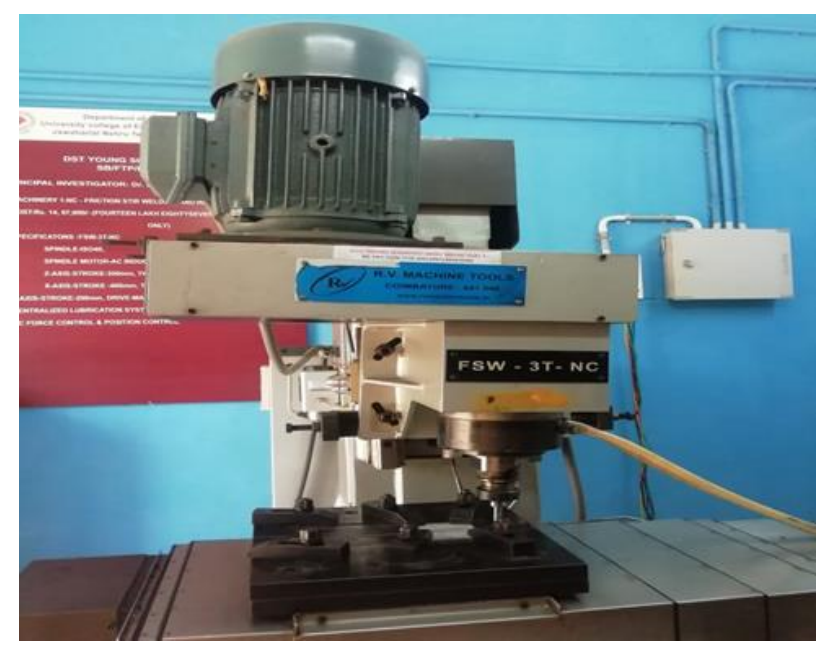

Figure 1 Friction Stir welding Setup

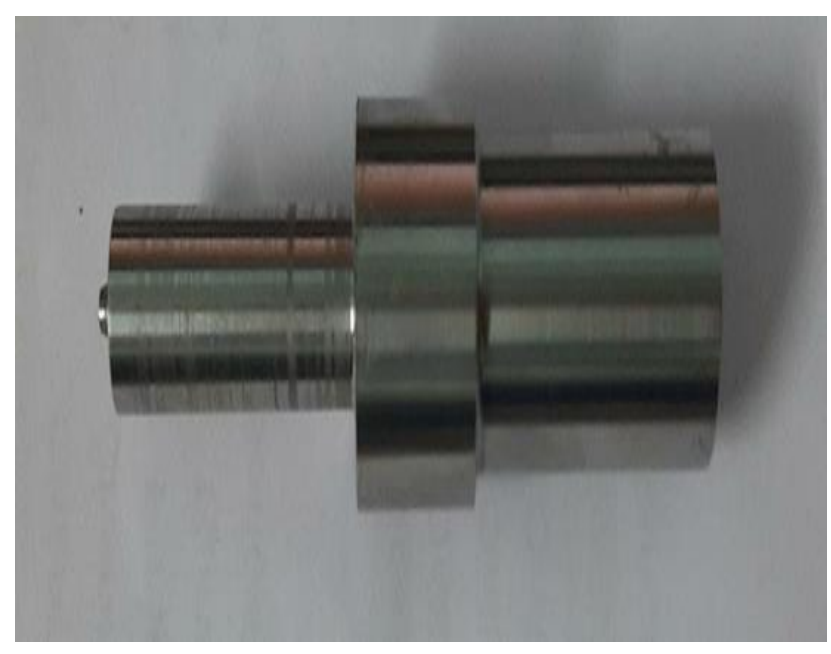

Figure 2 FSW Tool 
Table 2 Input process variables and their corresponding levels

\begin{tabular}{|l|l|c|c|c|}
\hline \multirow{2}{*}{ Parameters } & \multirow{2}{*}{ Symbol } & \multicolumn{3}{|c|}{ stages } \\
\cline { 3 - 5 } & & I & II & III \\
\hline Tool velocity & St & $800 \mathrm{rpm}$ & $900 \mathrm{rpm}$ & $1000 \mathrm{rpm}$ \\
\hline Welding speed & FW & $30 \mathrm{~mm} / \mathrm{min}$ & $40 \mathrm{~mm} / \mathrm{min}$ & $50 \mathrm{~mm} / \mathrm{min}$ \\
\hline Axial Force & Af & $300 \mathrm{~kg}$ & $400 \mathrm{~kg}$ & $500 \mathrm{~kg}$ \\
\hline
\end{tabular}

After welding, using wire EDM specimens for Tensile and microstructural analysis are cut perpendicular to the weld direction as per ASTM E8-4 from all nine samples. Tensile tests were conducted using Nano BISS 25KN fig.3 using $0.1 \mathrm{~mm} / \mathrm{min}$ as strain rate and Average Ultimate tensile strength and percentage of elongation was measured with three trails fig 4, using Digital micro hardness tester (HVS-100B model) was used to measure the micro hardness in the weld zone loading $200 \mathrm{gm}$ and a reside time of $15 \mathrm{sec}$ used to measure micro hardness at HAZ. Tensile test results, micro hardness along with theirs corresponding levels of process variables are listed in table. 3

Table 3 Experimental Trails using L9 orthogonal array and their response

\begin{tabular}{|c|c|c|c|c|c|}
\hline $\begin{array}{l}\text { Experiment } \\
\text { Number }\end{array}$ & $\begin{array}{l}\text { Tool } \\
\text { Velocity } \\
\left(\mathbf{T}_{\mathbf{s}}\right.\end{array}$ & $\begin{array}{l}\text { Welding } \\
\text { speed } \\
\left(\mathbf{F}_{\mathbf{w}}\right.\end{array}$ & $\begin{array}{l}\text { Axial } \\
\mathbf{l o a d} \\
\mathbf{A}_{\mathbf{l}}\end{array}$ & UTS & $\begin{array}{l}\text { HAZ } \\
\text { Micro } \\
\text { Hardness }\end{array}$ \\
\hline 1 & 1 & 1 & 1 & 131.54 & 65.74 \\
\hline 2 & 1 & 2 & 2 & 125 & 68.12 \\
\hline 3 & 1 & 3 & 3 & 126.13 & 63.41 \\
\hline 4 & 2 & 1 & 2 & 131.8 & 65.47 \\
\hline 5 & 2 & 2 & 3 & 100 & 76.77 \\
\hline 6 & 2 & 3 & 1 & 128 & 68.49 \\
\hline 7 & 3 & 1 & 3 & 117.5 & 77.03 \\
\hline 8 & 3 & 2 & 1 & 136.92 & 70.6 \\
\hline 9 & 3 & 3 & 2 & 140.95 & 75.49 \\
\hline
\end{tabular}

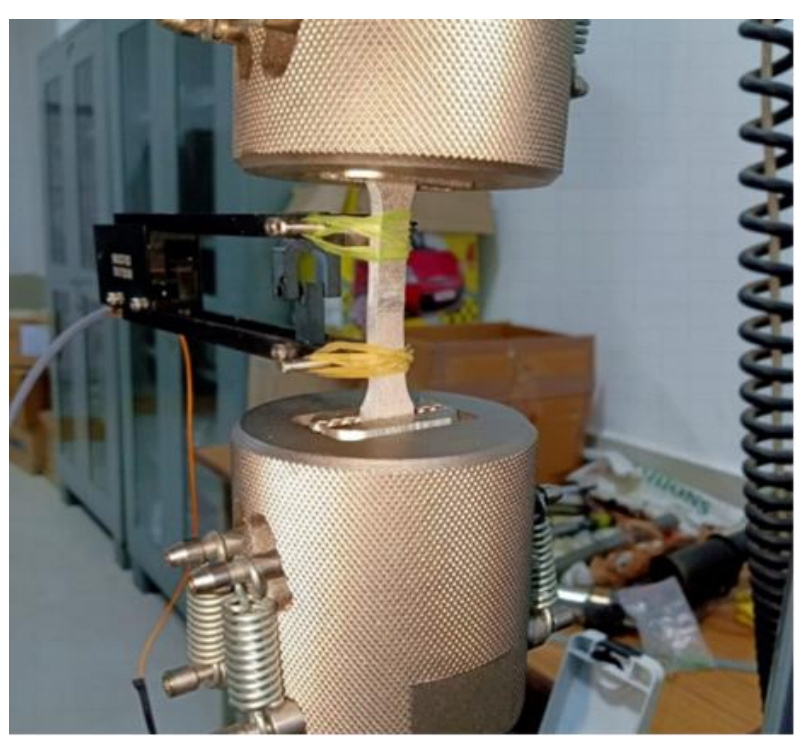

Figure 3 Tensile test setup 

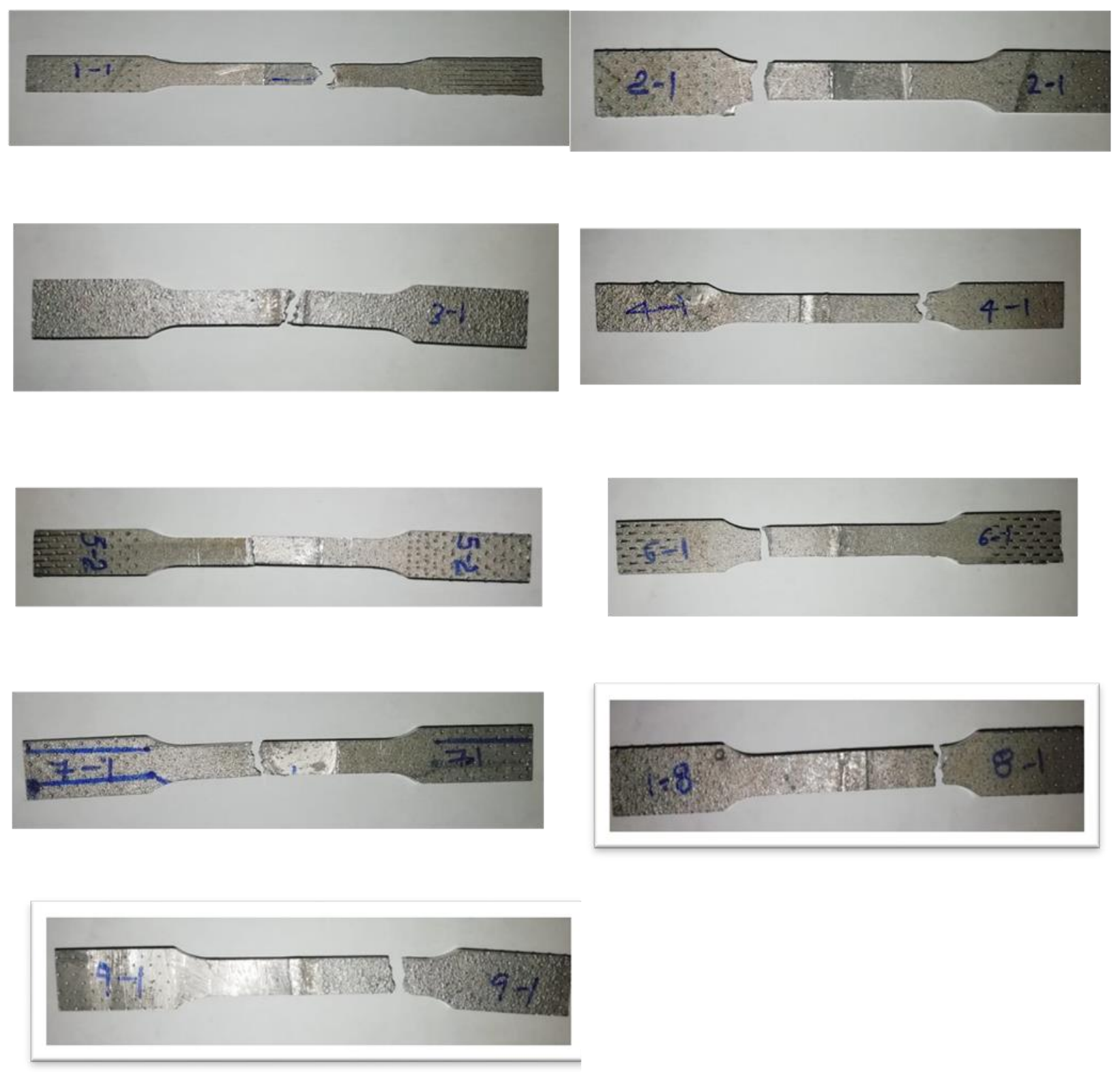

Figure 4 Tensile Test Samples

\subsection{Gray Relational Analysis}

Grey relational analysis technique has been used where $n=$ number of trails, yij $=$ detected response significance where $\mathrm{i}=1,2, \ldots \mathrm{n} ; \mathrm{j}=1,2 \ldots \mathrm{k}$ This is used to solve problems where the goal is to increase the quality of a desired characteristic. This is known as the larger-is-better scenario, and to be an important method for optimizing multiple responses. To find the optimum value in GRA, the sequence of steps are:

Step I S/N Ratios are determined by below equations

i) Higher is the better

$\mathrm{S} / \mathrm{N} \operatorname{ratio}(\boldsymbol{\eta})=-10 \log _{10}\left(\frac{1}{n}\right) \sum_{i=1}^{n} \frac{1}{x_{i j}^{2}}$

(This is known as the Higher - is - better scenario, in which the aim is to maximization of response.) 
where $n=$ the number of replicas, $x_{i j}=$ observed responses, where $i=1,2, \ldots n ; j=1,2 \ldots k$ This is useful for situations where the objective is to increase the quality parameter of interest. This is referred to as the "higher is better" situation.

ii) The lower the better.

$$
\mathrm{S} / \mathrm{N} \text { ratio }(\boldsymbol{\eta})=-10 \log _{10}\left(\frac{1}{n}\right) \sum_{i=1}^{n} x_{i j}^{2}
$$

(This is known as the smaller-is-better scenario, in which the aim is to minimization of response.)

Step II $\mathrm{x}_{\mathrm{ij}}$ is normalize as $\mathrm{Z}_{\mathrm{ij}}(0 \leq \mathrm{Zij} \leq 1)$ using the formula to minimize uncertainty and elude the impact of using diverse units Before using the grey relation theory or some other methodology to analyze the original data, it is important to normalize it. To make the sum of this array approximate to 1 , an equivalent value subtracted from the same list of values. We investigated the normalization process's sensitivity to the sequencing results, because the normalization process affects the rank. As a result, when using grey relation analysis to normalize data, we suggest using $\mathrm{S} / \mathrm{N}$ ratio value.

$$
Z_{i j}=\frac{x_{i j}-\min \left(x_{i j}, i=1,2, \ldots \ldots . . n\right)}{\max \left(x_{i j}, i=1,2, \ldots \ldots . . n\right)-\min \left(x_{i j}, i=1,2, \ldots \ldots . n\right)}
$$

(applied for $\mathrm{S} / \mathrm{N}$ ratio with higher is the better scenario)

$$
Z_{i j}=\frac{\max \left(x_{i j}, i=1,2, \ldots \ldots . n\right)-x_{i j}}{\max \left(x_{i j}, i=1,2, \ldots \ldots . n\right)-\min \left(x_{i j}, i=1,2, \ldots \ldots . n\right)}
$$

\section{(applied for $\mathrm{S} / \mathrm{N}$ ratio with Lower the better scenario)}

Step III Using the S/N ratio values that have been normalized, evaluate the grey relational co- efficient

$$
\gamma\left(x_{0}(k), x_{i}(k)\right)=\frac{\Delta \min +\xi \Delta \max }{\Delta_{0 j}(k)+\xi \Delta \max }
$$

\section{Where}

- $\quad \mathrm{J}=1,2,3 \ldots \mathrm{m}, \mathrm{n}$ are the number of experiments conducted and $\mathrm{m}$ is output response

- $x_{0}(k)$ is the reference sequence $\left(x_{0}(k)=1, \mathrm{k}=1,2,3 \ldots \mathrm{m}\right) ; x_{i}(k)$ is a particular comparison sequence.

- $\left.\Delta_{0 j}(k)=\| x_{0}(k)-x_{i}(k)\right) \|$ is The distinction between $\mathrm{x}_{0}(\mathrm{k})$ and $\mathrm{x}_{\mathrm{i}}(\mathrm{k})$ in absolute terms.

- $\left.\Delta \min =\min _{\forall j \in i} \min _{\forall k} \| x_{0}(k)-x_{i}(k)\right) \|$ is the smallest possible value for $\mathrm{x}(\mathrm{k})$

- $\left.\Delta \max =\min _{\forall j \in i} \min _{\forall k} \| x_{0}(k)-x_{i}(k)\right) \|$ is the largest value of $\mathrm{x}(\mathrm{k})$

- $\xi$ is the distinguishing coefficient, $\xi$, is within the given range $0 \leq \xi \leq 1$ (the coefficient may be modified depending on the system's practical needs).

Step IV obtain the Gray Relational Grade

$$
\overline{\gamma_{j}}=\frac{1}{k} \sum_{i=1}^{n} \gamma_{i j}
$$


where $\bar{\gamma}_{j}$ is grey relational rating for $\mathrm{j}^{\text {th }}$ trail, and number of output features are $\mathrm{k}$.

Step V Determine the best factor to use and the best degree combination for it.

Good product quality needs The greater the grey relational grade(GRG), as a consequence, the factor effect can be assessed using the GRG., similarly for each controllable factor, the optimal degree should be calculated.

For instance, to assess the impact of a factor $i$, we determine the average grade value(AGV) for each level $j$, and indicated as $\mathrm{AGV}_{\mathrm{j}}$, the effect, $\mathrm{E}_{\mathrm{i}}$, can be defined as

$\left.E_{i=\operatorname{Max}(A G V i j}\right)-\min (A G V i j)$

once we control factor $\mathrm{i}$, Finest value of $\mathrm{J}^{*}$ is obtained by

$\mathrm{j}^{*}=\max _{\mathrm{j}}(\mathrm{AGVij})$

\subsection{Implementation of the GRA}

Step I Using one of the Eqs (1), (2), compute S/N ratios of the initial conditions and the S/N ratios for a given response. Depending on what kind of quality characteristics you're looking for. Table 3 shows the computed S/N ratios related to each quality characteristic.

Step II S/N ratio values should be normalized by Eqs. (3), (4) and (5). Table 3 shows the results.

Step III The grey relational analysis should be carried out. using the information in Table 3, Using Eq, (6) compute the grey relational co-efficient using normalized S/N ratio values. $\xi$ can be assumed as 0.5 in Eq. (6) for this run. Since all process parameters are equally weighted, [10]. Table 4 summarizes the results.

Step IV The GRG can then be calculated using Eq. (7). then, grades are taken into account when attempting to solve the multiple-response parameter problem. Table 5 summarizes the findings.

Step V Maximum of grade values is taken into consideration (Table 5),,we can obtain optimal parameter conditions Ts3 Fw3 Al 2.

\subsection{Grey relational analysis}

Table 4 S/N Ratios and corresponding Normalized S/N ratios

\begin{tabular}{|l|l|l|l|l|}
\hline \multirow{2}{*}{$\begin{array}{l}\text { Experiment } \\
\text { number }\end{array}$} & \multicolumn{2}{|l|}{ S/N Ratios } & \multicolumn{2}{l}{ Normalized S/N ratios } \\
\cline { 2 - 5 } & UTS & $\begin{array}{l}\text { HAZ } \\
\text { Hardness }\end{array}$ & UTS & $\begin{array}{l}\text { HAZ } \\
\text { Hardness }\end{array}$ \\
\hline 1 & 42.3812 & -36.3566 & 0.7987 & 0.1855 \\
\hline 2 & 41.9382 & -36.6655 & 0.6501 & 0.3682 \\
\hline 3 & 42.0164 & -36.0432 & 0.6763 & 0.0000 \\
\hline 4 & 42.3983 & -36.3208 & 0.8045 & 0.1643 \\
\hline 5 & 40.0000 & -37.7038 & 0.0000 & 0.9826 \\
\hline 6 & 42.1442 & -36.7125 & 0.7192 & 0.3961 \\
\hline 7 & 41.4008 & -37.7332 & 0.4698 & 1.0000 \\
\hline 8 & 42.7293 & -36.9761 & 0.9155 & 0.5520 \\
\hline 9 & 42.9813 & -37.5578 & 1.0000 & 0.8962 \\
\hline
\end{tabular}


Table 5 Grey relational co-efficient and associated grey grade values

\begin{tabular}{|c|l|c|c|c|}
\hline \multirow{2}{*}{$\begin{array}{c}\text { Experiment } \\
\text { number }\end{array}$} & \multicolumn{2}{|c|}{$\begin{array}{c}\text { Grey relational co- } \\
\text { efficient }\end{array}$} & $\begin{array}{c}\text { grey grade } \\
\text { values }\end{array}$ & \\
\cline { 2 - 5 } & UTS & HAZ Hardness & Grade & Gray Order \\
\hline 1 & 0.7130 & 0.3804 & 0.3644 & 5 \\
\hline 2 & 0.5883 & 0.4418 & 0.3434 & 8 \\
\hline 3 & 0.6070 & 0.3333 & 0.3135 & 9 \\
\hline 4 & 0.7189 & 0.3743 & 0.3644 & 7 \\
\hline 5 & 0.3333 & 0.9664 & 0.4332 & 4 \\
\hline 6 & 0.6404 & 0.4529 & 0.3644 & 6 \\
\hline 7 & 0.4854 & 1.0000 & 0.4951 & 2 \\
\hline 8 & 0.8554 & 0.5274 & 0.4609 & 3 \\
\hline 9 & 1.0000 & 0.8281 & 0.6094 & 1 \\
\hline
\end{tabular}

Table 5 was used to compute the GRG means to each degree of controllable parameters, which were then summarized in Table 6. Highlighted values in Table 6 indicates larger GRG, the superior the compound performance characteristics. So, the controllable parameters' and their optimal values are: Tool velocity of $1000 \mathrm{rpm}$ (stage 3), feed rate of 50 $\mathrm{mm} / \mathrm{min}$ (stage 3 ), axil load of $400 \mathrm{~kg}$ (stage 2).

Table 6 Response table for GRG (grey relational grade)

\begin{tabular}{|l|c|c|c|c|c|}
\hline \multicolumn{1}{|c|}{ Parameters } & stage 1 & stage 2 & stage 3 & \multicolumn{2}{c|}{ Rank } \\
\hline Tool velocity & 0.340 & 0.387 & 0.522 & 0.181 & 1 \\
\hline Welding speed & 0.408 & 0.413 & 0.429 & 0.021 & 3 \\
\hline Axial Load & 0.397 & 0.439 & 0.414 & 0.042 & 2 \\
\hline
\end{tabular}

Table 6 shows the responses for Gray relational grade, Rotational speed has given rank 1, hence it has more influence on the tensile strength and hardness among three input parameters, as it causes more frictional heat input during welding. Large heat input causes grain refinement and leads to better Ultimate tensile strength and micro hardness. Next influential parameter among three is the Axial load raked 2, and the least influential parameter is the Feed Rate ranked 3.

\section{Results and discussion}

In this article, Using Taguchi's experimental design process, the parameters influencing the multiple performance characteristics of Friction stir welding of AlSi10Mg Casted alloy were investigated. For better multiple performance characteristics, the optimum Friction stir welding parameters were established. (Ultimate Tensile strength, Micro hardness) in the FSW process with the aid of grey relational analysis. Where three separate controllable parameters are used, this study suggests using an orthogonal array in conjunction with GRA to optimize multiple performances of the FSW process: Tool velocity, Feed rate, and Axial Load. Since tool velocity is a major factor in heat generation near the weld zone, tool velocity was considered a sensitive parameter in the FSW phase. At low tool velocity, heat generation is limited, resulting in poorer plastic deformations and weld region is sufferers with insufficient material flow, lowering hardness. However, with greater tool velocity, the heat produced increases, causing turbulence to form coarse grains. As a result, the hardness of the material is reduced. As welding speed increases, the hardness values decreases. [11]. 


\section{Conclusion}

- Looking at GRG values and table 6 reveals that higher GRG aims better multiple response. As a result, ideal levels in FSW of AlSi10Mg casted alloy for the combination of desired output characteristics Ts3 Fw3 Al 2 parameters. With this combination it is possible to get more Ultimate tensile strength and reasonable Micro hardness in the heat effected zone of FSWed joint.

- 2 According to the GRG findings, tool velocity, axial load, and Axial load have a significant impact on different responses.

- This work can be considered as reference to establish the optimized process parameters for joining Additive Manufactured AlSi10Mg.

\section{Compliance with ethical standards}

\section{Acknowledgments}

Authors would like to thank SAGTE for sponsoring in carrying out this work.

\section{Disclosure of conflict of interest}

All authors declare that they have no conflict of interest.

\section{References}

[1] Xie GM, Ma ZY, Geng L. Development of a fine-grained microstructure and the properties of a nugget zone in friction stir welded pure copper. Scripta Materialia. 2007; 57(2): 73-76.

[2] Ammar H, Samuel A, Samuel F. Porosity and the fatigue behavior of hypoeutectic and hypereutectic aluminumsilicon casting alloys, International Journal of Fatigue. 2008; 30(6): 1024-1035.

[3] Braun R, Dalle Donne C, Staniek G. Laser beam welding and friction stir welding of 6013-T6 aluminum alloy sheet. Materialwiss. Werkstofftech. 2000; 31: 1017-26.

[4] Charit I, Mishra RS, Mahoney MW. Multisheet structures in 7475 aluminum by friction stir welding in concert with post-weld superplastic forming. Scr Mater. 2002; 47: 631-6.

[5] Rhodes CG, Mahoney MW, Bingel WH. Effects of friction stir welding on microstructure of 7075 aluminum. Scr Mater. 1997; 36: 69-75.

[6] Liu G, Murr LE, Niou CS, McClure JC, Vega FR. Micro-structural aspects of the friction-stir welding of 6061-T6 aluminum alloy. Scr Mater. 1997; 37: 355.

[7] Murr LE, Liu G, McClure JC. Dynamic recrystallization in friction-stir welding of aluminum alloy 1100. J Mater Sci Lett. 1997; 16: 1801.

[8] Kavimani KS. Prakash, Tribological behaviour predictions of r-GO reinforced Mg composite using ANN coupled Taguchi approach, J. Phys. Chem. Solids. 2017; 110: 409-419.

[9] V Kavimani, K. Soorya Prakash, T Thankachan. Multi-objective optimization in WEDM process of graphene - SiCmagnesium composite through hybrid techniques, Meas. J. Int. Meas. Confed. 2019; 145: 335-349.

[10] Tosun N. Determination of optimum parameters for multiperformance characteristics in drilling by using grey relational analysis. Int J Adv Manuf Technol. 2006; 28: 450-455.

[11] PM Gopal K Soorya Prakash. Minimization of cutting force, temperature and surface roughness through GRA, TOPSIS and Taguchi techniques in end milling of Mg hybrid MMC, Measurement. February 2018; 116: 178-192. 


\section{Author's short biography}

\begin{tabular}{|l|l|}
\hline & $\begin{array}{l}\text { Mr. G. Balakrishna, M.E, working as Assistant professor, he has } 12 \text { years of } \\
\text { teaching experience in teaching. }\end{array}$ \\
\hline
\end{tabular}

